\title{
Nautical Risk Assessment for LNG Operations at the Port of Koper
}

\author{
Marko Perkovic ${ }^{1, *}$ - Lucjan Gucma ${ }^{2}$ - Marcin Przywarty² - Maciej Gucma ${ }^{2}$ - Stojan Petelin ${ }^{1}$ - Peter Vidmar ${ }^{1}$ \\ 1University of Ljubljana, Faculty of Maritime Studies and Transport, Slovenia \\ 2Maritime University of Szczecin, Poland
}

Construction of an LNG (Liquid Natural Gas) terminal by TGE (TGE Gas Engineering GmbH) is currently planned to be located along the Slovenian coast near the city of Koper. Two other LNG terminals are also plannedl: one in the Trieste port and the other off shore in Trieste Bay in Italy. Focusing on nautical operations, the purpose of this paper is to identify potential risks and to assess their levels as consequences of increased LNG activities. The ports in the area are host to a variety of vessels, including containers, tankers and chemical carriers, general cargo vessels, passenger ferries, bulk carriers, ro-ro carriers, etc.; and a large number of recreational and fishing vessels can be located on the navigational line towards ports located in Trieste bay. There are around 2500 vessels calling at the Port of Koper a year and approximately the same number at the Port of Trieste as well as a few hundred more nearby at the Port of Monfalcone. Using a quantitative approach, collision and grounding risk assessment will be analyzed for the shipping situation in the area, obtained through AIS (Automatic Identification System).

Keywords: LNG terminal, shipping, accidents, risk

\section{O INTRODUCTION}

On the Slovenian coast near the city of Koper an LNG (Liquefied Natural Gas) terminal is planned to be built by TGE. This LNG terminal will have a throughput of 5 billion $\mathrm{Nm}^{3} / y e a r$. To enable this throughput a jetty will be constructed at the end of mole II between basin 2 and basin 3 (Fig. 1) for the import of LNG using specialised LNG carriers [1].

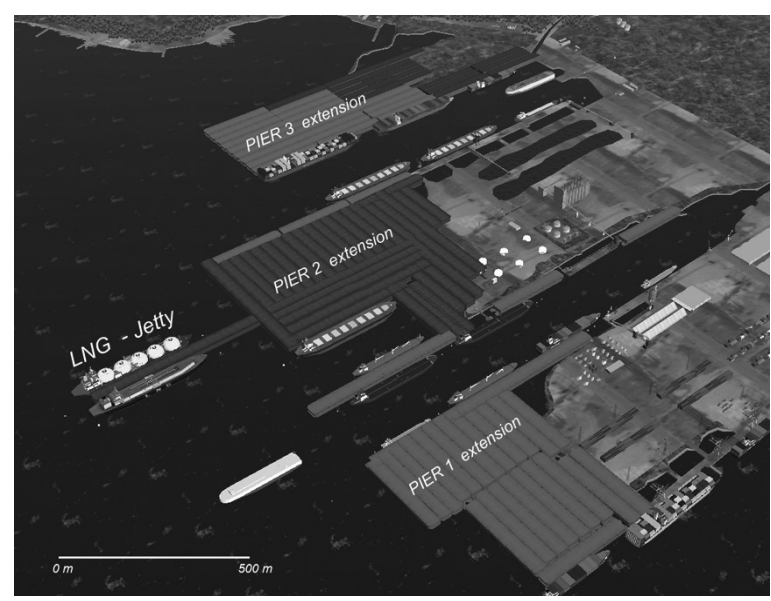

Fig. 1. Location of proposed LNG terminal

At the north side of this jetty, LNG carriers (LNGC) with capacities varying from $70,000 \mathrm{~m}^{3}$ to $220,000 \mathrm{~m}^{3}$ will berth and unload LNG. From the jetty an above-ground pipeline will transport the LNG up to the western end of mole II. Here, the pipeline will go underground and transport the LNG further to the LNG terminal where the LNG will be stored in LNG tanks. From these tanks liquid natural gas will be gasified and exported to the external gas pipeline distribution system. A similar layout is envisioned for Trieste by the German utility group E.ON. A special off shore terminal - though not floating - is planned to be located in the middle of Trieste bay [2].

To identify and assess the nautical level of risk of the LNG activities a risk study has been performed focusing on the nautical operations of the foreseen LNG activities in the bay and the Port of Koper [2] to [4]. This risk assessment compares the risks in the Port of Koper and in the bay following potential accidents/collisions with an LNG carrier.

\section{SETTING THE SCENE}

\subsection{Activities in the Port of Koper}

The Port of Koper, as the lone port of a sovereign nation is as it must be a multipurpose port, equipped and prepared for handling and warehousing all types of goods. The basic port activities are carried out at specialized terminals, which are technologically and organizationally suitable for handling and warehousing specific cargo groups. Fig. 2 gives information about the throughput of various types of cargo, by not actually providing an overall picture of the port, its capacities, complications and specific circumstances.

Just as the Adriatic is a shallow finger of the Mediterranean, the bay of Koper is shallow - Koper is a shallow port with many traffic constraints and challenges. The region also combines typical northern Mediterranean weather and a micro-climate that includes the burja (bora) wind as the chief obstacle 
to easy ingress and egress, as well as local variants on the typical storms and winds of the Mediterranean. As the sole port for Slovenia, it must handle every type of cargo that is traded by ship, those listed or implied in Fig. 2, along with refrigerated consumables, timber, specific bulk cargos like coal and iron, innumerable minerals and foodstuffs, sandy alumina (with a 20,000 ton capacity silo), as well as livestock.

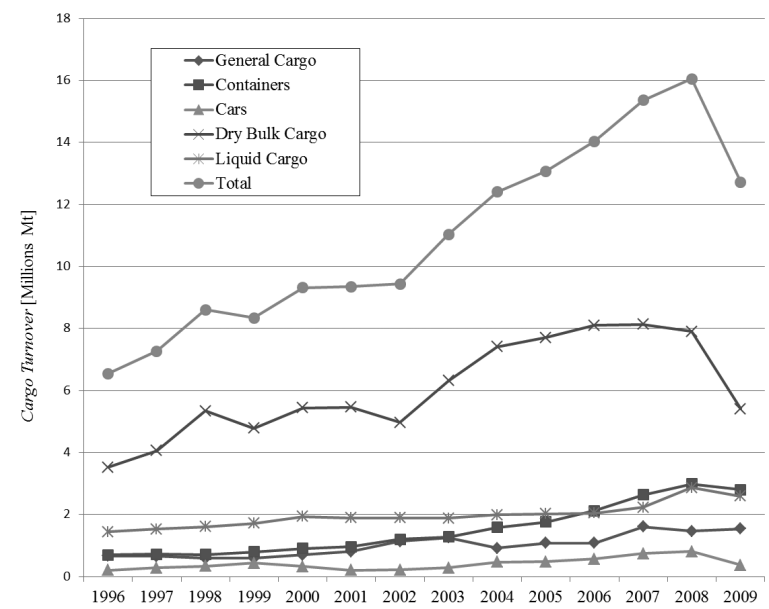

Fig. 2. Maritime cargo throughput in tons

The Port of Koper is therefore a relatively small and shallow bay with terminals for virtually all of the country's imports and exports with a notable exception of LNG. Traffic includes a variety of ship sizes, for the most part limited on its larger side only by the depth of the Adriatic and its ports in general Koper is just a single peninsula southwest of the port of Trieste, and in fact Trieste is often used as the point of orientation for port workers such as pilots and tug captains. Given the variety of cargo types, there is also a tremendous variety of ship types, converted vessels, some of the oldest seagoing vessels, as well as the newest. Being so close to the waters of two different countries, and especially so close to Trieste, traffic considerations do not begin or end at the port itself, but must be considered beyond the bay as well [5].

\subsection{Traffic in the Area}

Traffic have been analyzed on the basis of AIS research (Fig. 3). Vessel passages are checked in 6 gates;

\footnotetext{
$1 \quad 45^{\circ} 33.14^{\prime} \mathrm{N}$; $13^{\circ} 28.21^{\prime} \mathrm{E}$ (center of $N E$ bound traffic lane)

$2 \quad 45^{\circ} 34.48^{\prime} \mathrm{N} ; 1^{\circ} 39.60^{\prime} \mathrm{E}$ (center of inbound traffic lane to Koper)
}

$3 \quad 45^{\circ} 35.81^{\prime} \mathrm{N}$; $13^{\circ} 39.53^{\prime} \mathrm{E}$ (center of outbound traffic lane from Koper)

$4 \quad 45^{\circ} 36.71^{\prime} \mathrm{N}$; 133․ ${ }^{\circ} 32^{\prime} \mathrm{E}$ (in precaution area, approximate center of prolonged traffic lane to Trieste)

$5 \quad 45^{\circ} 37.86^{\prime} \mathrm{N}$; 13 $3^{\circ} 33.07^{\prime} \mathrm{E}$ (center of $S W$ bound traffic lane)

$6 \quad 4^{\circ} 35.88^{\prime} \mathrm{N}$; $13^{\circ} 26.38^{\prime} \mathrm{E}$ (center of $S W$ bound traffic lane)

xkp $45^{\circ} 37.68^{\prime} \mathrm{N}$; $13^{\circ} 35.59^{\prime} \mathrm{E}$ (center of precaution area)

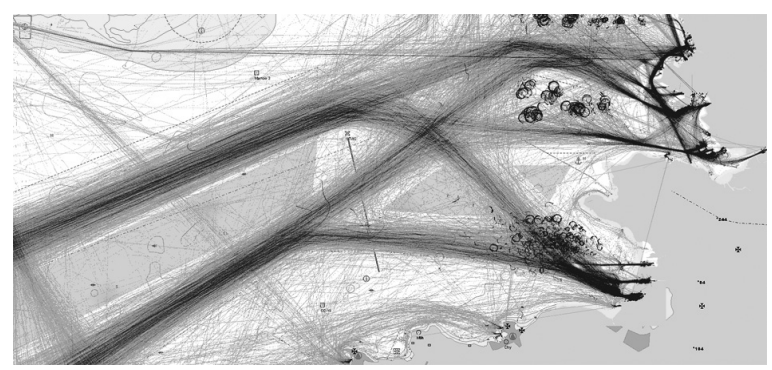

Fig. 3. Actual AIS tracks in the area

Positions of AIS gates and modeled routes are depicted in Fig. 4, where traffic is analyzed for;

A Incoming vessels with destination:

- Koper crossing gates no. 1 and 2,

- Trieste or Monfalcone crossing gates no. 1 and 4 ,

B Outgoing vessels sailing from:

- $\quad$ Koper crossing gates no. 3, 5 and 6,

- Trieste or Monfalcone crossing gates no. 5 and 6 ,

C Vessels from Koper to Trieste or Monfalcone crossing only gate no. 3 ,

D Vessels from Trieste/Monfalcone to Koper crossing gates no. xkp and 2.

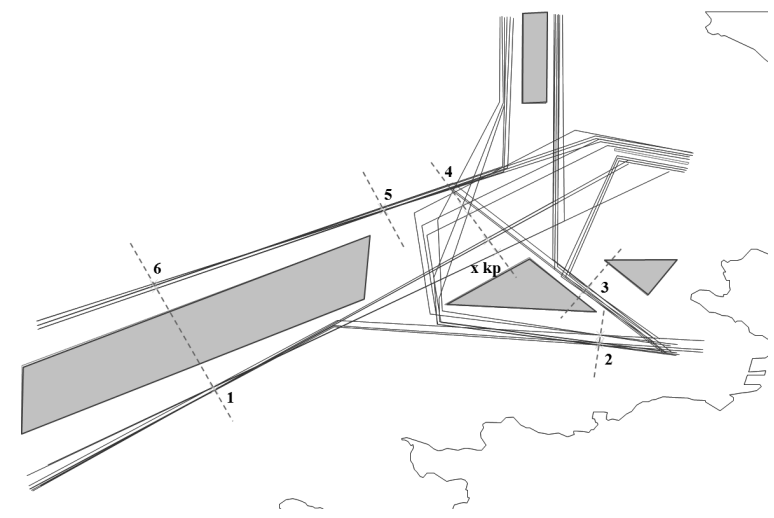

Fig. 4. AlS Observation gates and modeling routs 
For each vessel course, speed and distance to check point at the time of crossing the perpendicular line to the direction of traffic flow have been measured (Fig. 5). On the basis of AIS measurements ship routes have been determined. After an analysis due to different behavior of navigators on different sizes of ships, routes have been analyzed for three different ship sizes separately (up to $120 \mathrm{~m}, 120$ to $180 \mathrm{~m}$ and over $180 \mathrm{~m}$ in length). The AIS research enabled the evaluation of two probabilistic parameters of ships routes: mean and standard deviation of Way Points in given routes. Traffic on the routes has been modeled with the use of the Poisson distribution and Way Points have been modeled by 2-dimensional normal distribution with mean and standard deviation assessed from AIS data.

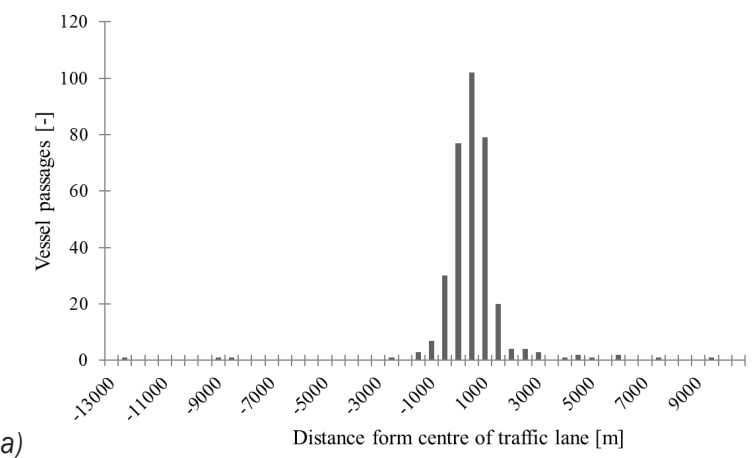

b)
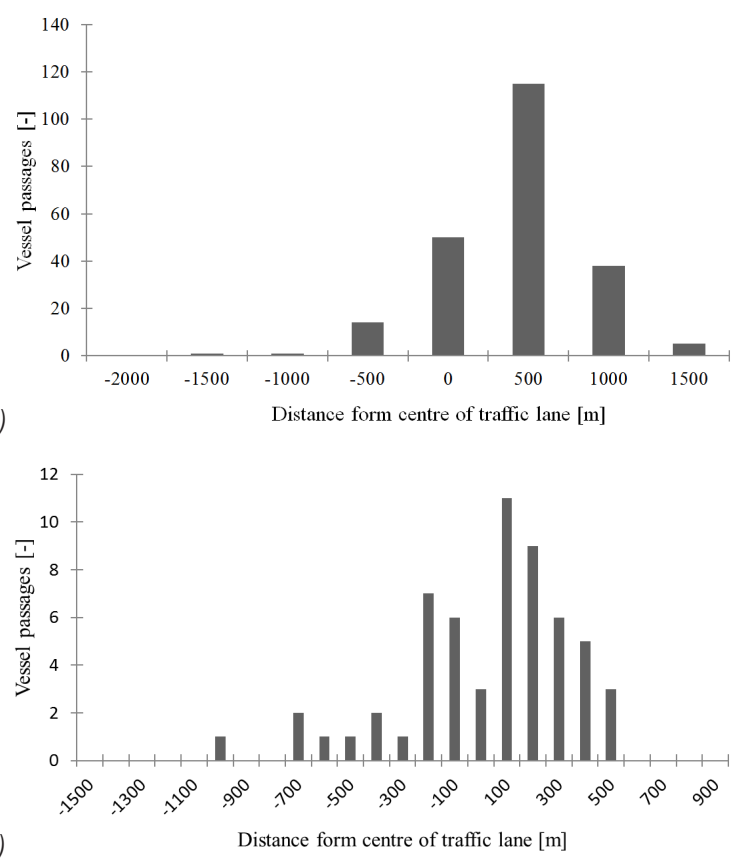

Fig. 5. Histogram function of ships variability from route on AIS Gate no. 1 for three different sizes; a) up to $120 \mathrm{~m}$, b) 120 to $180 \mathrm{~m}, \mathrm{c}$ ) over $180 \mathrm{~m}$ in length
The graphs (Fig. 5) show the number and type of vessels entering and leaving the Port of Koper for each basin.

For the purpose of grounding in the port vicinity and collision risk assessment with LNG jetty several additional parameters are considered such as: vessel type, draught, pilotage and tug escorting status, approaching course and speed and anchorage occupancy. Fig. 6 presents the yearly period during which vessels are grouped by size and type for basin 1. The same data collection approach was used for basin 2 and 3. Fig. 7 presents control lines and sample data for one approaching vessel.

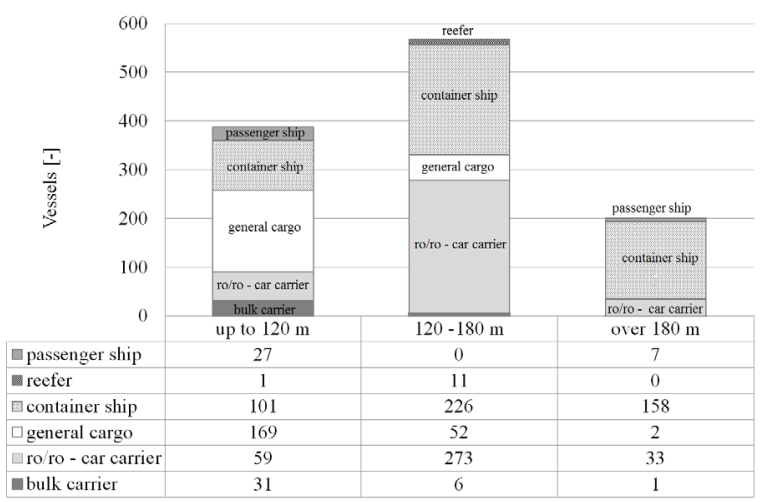

Fig. 6. Vessels by size and type entering and leaving Port of Koper basin 1

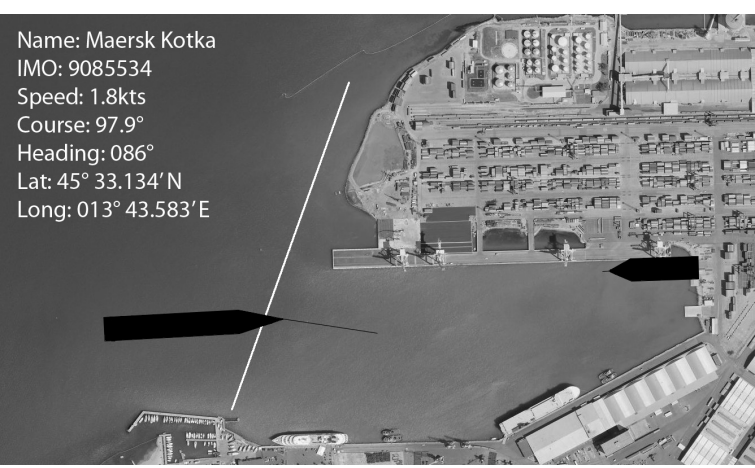

Fig. 7. Vessels by size and type entering and leaving Port of Koper basin 1

\section{METHODOLOGIES}

One of the most appropriate approaches to assessing the safety of complex marine traffic engineering systems is the use of stochastic simulation models [6]. The model can be used for almost all navigational accident assessments, such as collisions between vessels, groundings, collisions with fixed objects, indirect accidents such as those involving anchors or 
accidents caused by ship generated waves [7]. The model could comprise several modules responsible for different navigational accidents.

The design of the collision model was divided into 4 stages. The main goal of this model is to calculate the probability of collision for a given type of encounter. Because there are no statistical data about collisions in the Gulfs of Trieste and Koper the probability calculated for the Baltic Sea was used [8].

Stage I: Division of the encounters into characteristic types

- Head-on encounter - difference of headings 170 to $190^{\circ}$ and distance less than critical.

- Overtaking - difference of headings more than $350^{\circ}$ or less than $10^{\circ}$ and distance less than critical.

- Crossing - difference of headings (rest of cases) and distance less than critical.

The critical distances where navigators perform anti-collision manoeuvres was assumed on the basis of expert opinions separately for each type of encounter presented by Table 1 where $L_{\max }$ correspond to the length of bigger ship.

Table 1. Critical distances where navigators perform anti-collision manoeuvres

\begin{tabular}{lcc}
\hline \multirow{2}{*}{ Type of encounter } & \multicolumn{2}{c}{ Distance } \\
\cline { 2 - 3 } & $\begin{array}{c}\text { Good } \\
\text { visibility }\end{array}$ & $\begin{array}{c}\text { Restricted } \\
\text { visibility }\end{array}$ \\
\hline Head on (port/port-side) & $2.5 L_{\max }$ & $5 L_{\max }$ \\
\hline Head on (starboard/strb-side) & $5 L_{\max }$ & $10 L_{\max }$ \\
\hline Overtaking & $2.5 L_{\max }$ & $5 L_{\max }$ \\
\hline Crossing & $5 L_{\max }$ & $10 L_{\max }$ \\
\hline
\end{tabular}

Stage II: Calculation of the number of encounters of each type.

For the southern part of the Baltic Sea - the overall number of encounters estimated by the simulation model is around 140,000 per year, $30 \%$ of them headon situations, $40 \%$ crossing and $30 \%$ overtaking. This could be done for the Gulf of Trieste, but due to the lack of collision data it would be pointless.

Stage III: Study of the statistical data and evaluation of the intensity of collisions.

For the southern part of the Baltic Sea the mean intensity of collision accidents equals 2.2 per year. Only open sea area accidents were considered.

Stage IV: Calculation of the probability of collision for a given type of situation.

To simplify the calculations it was assumed that the intensity of a collision is equal in all considered situations. The existing databases of real accident scenarios justifies this assumption:
- head-on encounter: 0.73 collisions per year,

- overtaking: 0.73 collisions per year,

- crossing: 0.73 collisions per year.

The probability of collision for a given type of encounter can be calculated by using the Eq. (1):

$$
P c=\frac{C_{I}}{n_{E S}},
$$

where $P c$ is the probability of collision for a given type of encounter, $C_{I}$ intensity of collision for given type of encounter and $n_{E S}$ number of encounters of a given type.

The number of ships navigating on a given route, in cases when vessels have freedom of selecting their speed, route and time of departure can be described as a stationary Poisson distributed stochastic process, where probability of appearance of $k$ ships in one step of simulation equals:

$$
P(X=k)=\frac{\lambda^{k} e^{-\lambda}}{k !},
$$

where $k$ is the number of ships navigating on a given route in one step of simulation, and $\lambda$ the expected number of ships that occur during that one step of simulation.

The probability that in one step no ship will appear on a given route equals:

$$
P(X=0)=e^{-\lambda} \text {. }
$$

If the assumption of freedom of traffic cannot be accepted, the non-homogeneous Poisson process should be used. Let us assume that on the given route in a period $T$ of time $I$ ships appear. Period $T$ is divided into sections $\left(t_{1}, t_{2}\right],\left(t_{2}, t_{3}\right] \ldots\left(t_{n-1}, t_{n}\right]$ with the same length $\Delta t$ where $t_{1}=0$ and $t_{n}=T$. Since the $n_{1}, n_{2}$, $\ldots, n_{m}$ is the number of ships navigating in a particular section, the total number of ships equals:

$$
n_{a}=\sum_{i=1}^{m} n_{i}
$$

Let us assume that the ship traffic flow process derives from NHPP. The rate of number of ships $\lambda(t)$ is considered as constant in a given section. The average intensity function in a given section is the rate of the number of ships per unit of period, the maximal likelihood estimator is the average rate of number of ships in a section normalized to the length of the section:

$$
\hat{\lambda}(t)=\frac{n_{i}}{I\left(t_{i}-t_{i-1}\right)}, \quad t_{i-1}<t \leq t_{i}, \text { for } i=1,2, \ldots, m .
$$

The associated cumulative distribution is: 


$$
\hat{\Lambda}(t)=\left(\sum_{j=1}^{i-1} \frac{n_{j}}{I}\right)+\frac{n_{i}\left(t-t_{i-1}\right)}{I\left(t_{i}-t_{i-1}\right)}, \quad t_{i-1}<t \leq t_{i}
$$

It should be noted that if there are no accidents in a given interval the cumulative function estimate is constant. The non-parametric confidence interval for such cumulative intensity function can be expressed by the following expression:

$$
\hat{\Lambda}(t)-z_{\alpha / 2} \sqrt{\frac{\hat{\Lambda}(t)}{I}}<\Lambda(t)<\hat{\Lambda}(t)+z_{\alpha / 2} \sqrt{\frac{\hat{\Lambda}(t)}{I}},
$$

for $0<t<T$, where $z_{\alpha / 2}$ is the $1-\alpha / 2$ fractal of the standard normal distribution.

Spatial distribution is one of the main parameters describing traffic flow. It describes the ship's hull position relative to the axis of the route. The information about the position of the vessel's center of gravity, the shape of the waterline and the course are used to define the distribution. It should be noted that different types of distributions are used depending on the type and shape of the waterway like: normal, logarithmic, logistic or triangular distribution. Here normal distribution with PDF (probability density function) was used:

$$
d_{l}(y)=\frac{1}{\sigma_{l} \sqrt{2 \pi}} e^{-\frac{\left(y-m_{l}\right)^{2}}{2 \sigma_{l}^{2}}}
$$

where $y$ is distance to the axis, $m$ average of ship's distance to the waterway axis, $\sigma$ standard deviation of ship's distance to the waterway axis..

Coordinates of Way Points are modeled using two-dimensional normal distribution. Each coordinate of each Way Point for a ship on a given route is generated separately with the use of the following formula:

$$
f(x)=\frac{1}{\sigma \sqrt{2 \pi}} e^{-\frac{(x-\mu)^{2}}{2 \sigma^{2}}},
$$

where $\mu$ is the mean coordinate (latitude, longitude) of Way Point, and $\sigma$ standard deviation.

\section{RESULTS}

The AIS tracks and LNG locations for the foreseen offshore terminal located at the separation zone are presented in Fig. 8. The figure shows the initial position located inside the precautionary area and then the second location chosen after it was determined that the first was inappropriate.
Following are the results for the traffic analyzed for the complete area (Trieste bay) presented in Fig. 8 and further analyzed for the inbound (green) traffic lane calling at the Port of Koper and the outbound traffic lane (orange) corresponding to the departure passage.

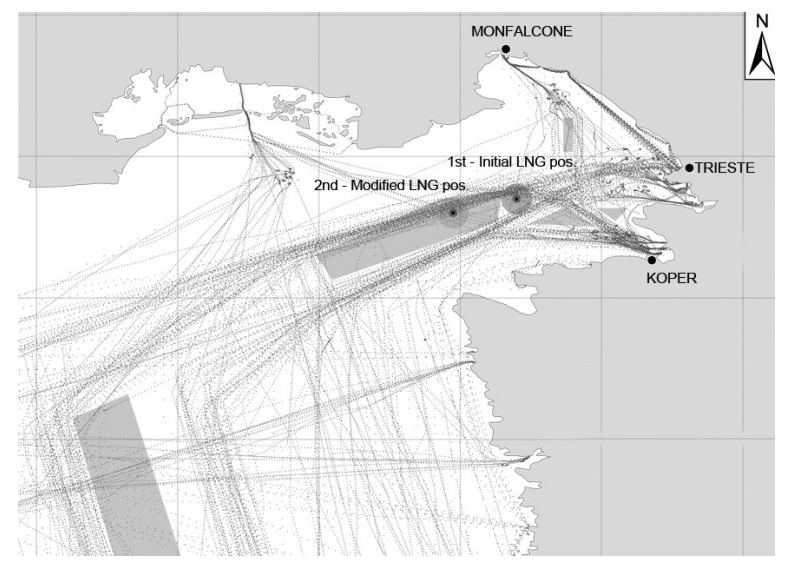

Fig. 8. AIS base traffic and two locations for offshore terminal

\subsection{Existing Traffic in the Bay}

Existing traffic for the Port of Koper (which includes traffic destined to Trieste and departing from Trieste) was analyzed by performing 40,000 simulations ( 800 per year over 5 years). The results are presented in Fig. 9 and Table 2. As illustrated, the departure area is more risky due to the fact that in this direction vessels cross the precautionary area.

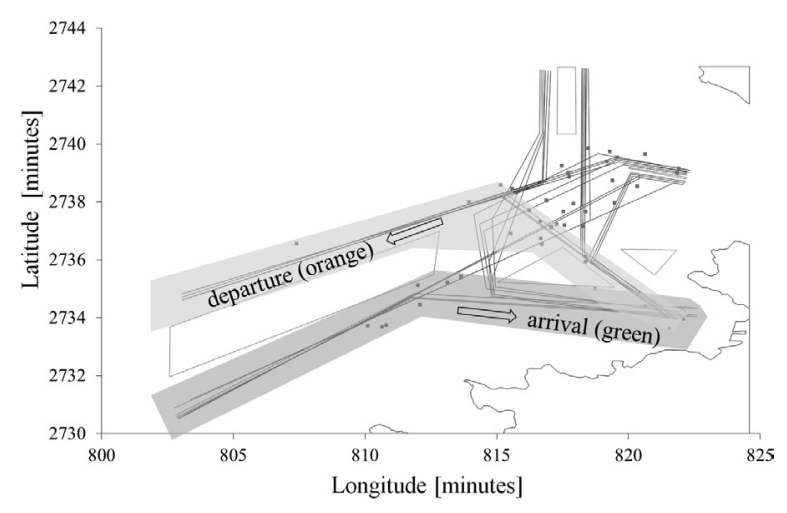

Fig. 9. Simulated places of collisions during $(800 \times) 5$ years period

\subsection{Offshore Location}

The location of an LNG terminal in the center of the existing TSS was also analyzed (Fig. 10 and Table 3 ). For that purpose it was necessary to widen the TSS. The model demonstrates that the mean time 
between collisions has increased (from 80 to 112.68 years) meaning that expanding the TSS can contribute towards safety at sea.

Table 2. Mean number of accidents, probability of accidents and mean time between accidents

\begin{tabular}{lcccc}
\hline & $\begin{array}{c}\text { Number of } \\
\text { simulations } \\
\text { per year }\end{array}$ & $\begin{array}{c}\text { Total } \\
\text { number of } \\
\text { collision }\end{array}$ & $\begin{array}{c}\text { Expected number } \\
\text { of collisions } \\
\text { [year-1] }\end{array}$ & $\begin{array}{c}\text { Mean time } \\
\text { between } \\
\text { collisions }\end{array}$ \\
\hline $\begin{array}{l}\text { Complete } \\
\text { Area }\end{array}$ & 800 & 50 & 0.0125 & 80 \\
\hline Arrival & 800 & 13 & 0.00325 & 308 \\
\hline Departure & 800 & 27 & 0.00675 & 148 \\
\hline
\end{tabular}

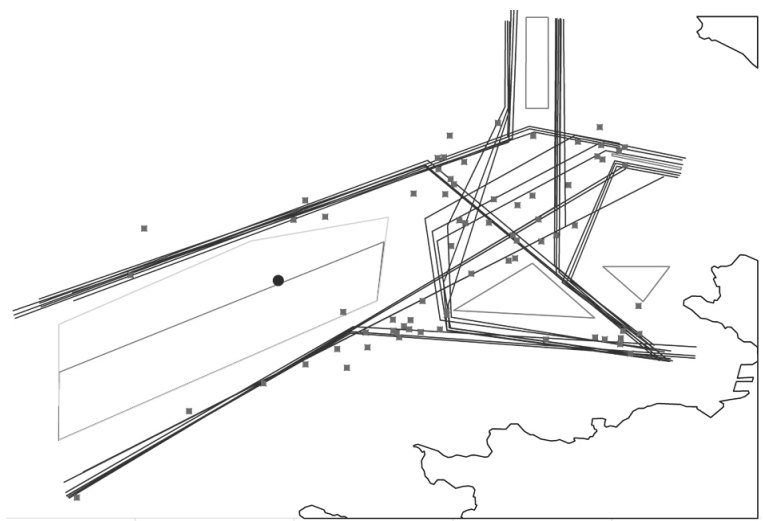

Fig. 10. Simulated places of collisions in scenario 1 during $1600 \times 5$ years period with modified TSS and offshore LNG terminal as an obstruction

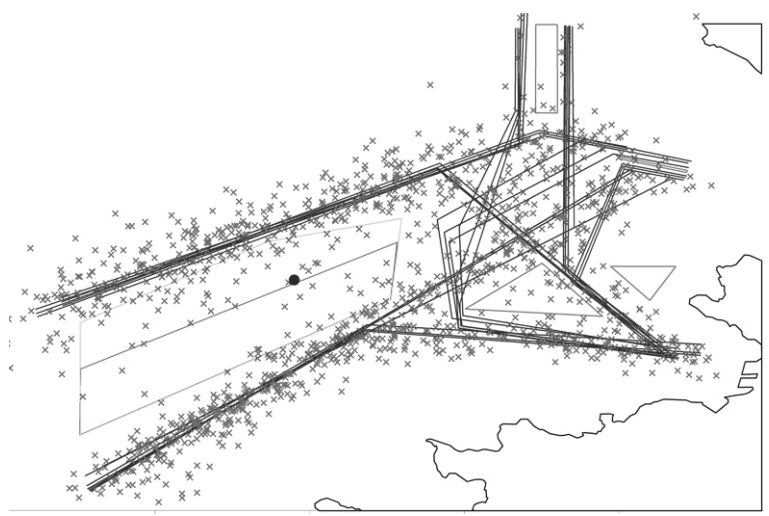

Fig. 11. Simulated places of ME failures in scenario 1 (no increase of traffic) during $1600 \times 5$ years period

Further, the location of the LNG terminal was analyzed as an obstruction [9] and [10] relevant to instances of Main Engine failures. Statistics for ME failures were used from MEHRA [11]. Fig. 12 shows that some ME failures can result in collisions with the terminal. The LNG terminal is presented as a dot in the separation area (Fig. 11). ME failures inside the safety domain of the LNG terminal have potential for collisions. In that case considering a safety domain with a diameter of $3 \mathrm{NM}$ suggests that only around $15 \%$ of total expected failures in the analyzed area can result in a collision. Complete results are presented in Table 3.

\subsection{The Koper Area}

On the basis of AIS measurements the routes of ships have been determined before Koper. Due to a very low number of simulated collisions the risk of collision can be described by the number of encounter situations (Fig. 12). For the Port of Koper the model of grounding was applied with the assumption that the probability of an accident depends on the distance to the given safety contour (or shore).

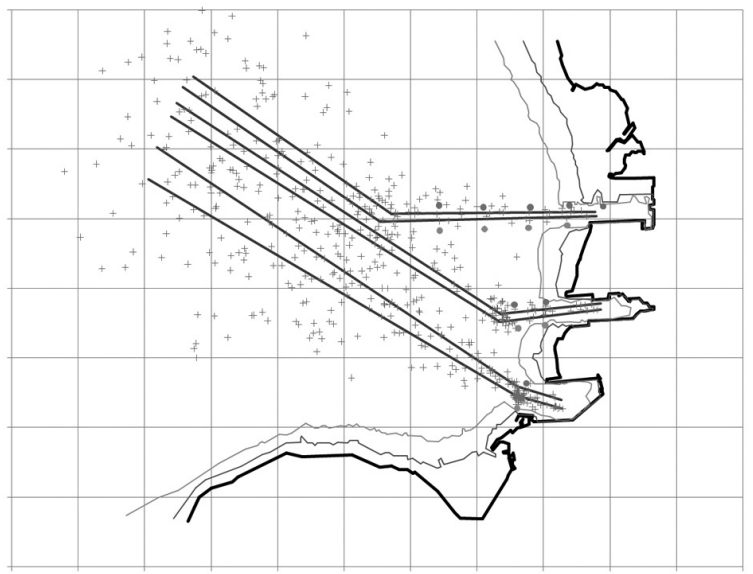

Fig. 12. Simulated encounter situations [5 years]

Numerical results are presented in Table 3. It is evident that the collision period is seriously lower than for the offshore location. At the same time vessel speeds are slower in the port vicinity, so the consequences can not be the same as for the offshore location where traffic moves at "sea speed". By implementing this severity factor the mean time

Table 3. Mean number of accidents, probability of accidents and mean time between accidents

\begin{tabular}{cccccccc}
\hline & $\begin{array}{c}\text { Number of } 5 \\
\text { year simulation } \\
\text { periods }\end{array}$ & $\begin{array}{c}\text { Total } \\
\text { number of } \\
\text { collisions }\end{array}$ & $\begin{array}{c}\text { Expected number } \\
\text { of collisions per } \\
\text { year }\end{array}$ & $\begin{array}{c}\text { Mean time } \\
\text { between collisions } \\
\text { [year] }\end{array}$ & $\begin{array}{c}\text { Total number of } \\
\text { ME failures }\end{array}$ & $\begin{array}{c}\text { Expected } \\
\text { number of ME } \\
\text { failures per year }\end{array}$ & $\begin{array}{c}\text { Mean time } \\
\text { between ME } \\
\text { failures }\end{array}$ \\
\hline Existing traffic & 1600 & 71 & 0.008875 & 112.68 & 1343 & 0.167875 & 5.96 \\
\hline
\end{tabular}


between collisions rises to 265 years, compared to offshore at 80 years or 71 collisions if the traffic separation area is extended in width.

Table 4. Estimated collisions and grounding factors

\begin{tabular}{lcc}
\hline \multicolumn{1}{c}{ Name } & Value & unit \\
\hline Probability of collision & 0.00002 & \\
\hline Collision intensity per year & 0.0378 & [1/year] \\
\hline Collision period & 26.5 & [years] \\
\hline Severe collision factor & 0.1 & \\
\hline Severe collision period & 265 & [years] \\
\hline Grounding intensity per year & 0.11 & [1/year] \\
\hline Grounding period & 9.1 & [years] \\
\hline Severe grounding factor & 0.1 & \\
\hline Severe grounding period & 90 & [years] \\
\hline
\end{tabular}

\section{CONCLUSIONS}

The results presented in Figs. 8 to 10 and Table 1 to 3 provide a general overview of collision risk spots in the analyzed area. The most risk-affected place in the analyzed area is the precaution area near AIS gate $\mathrm{xkp}$. This area should be covered and protected by future VTS with special care. The ships in this area significantly change courses, forcing other ships to predict their maneuvers. New routing measures could be considered in this place in the future to increase navigational safety (e.g., roundabout traffic scheme). But this is standard traffic risk analysis with no bearing on the question of any specific type of vessel unless we consider abnormalities of size and maneuverability.

For the present purposes it is significant is that traffic increases in the ports of Koper and Trieste expected to result from the installation of $\mathrm{LNG}$ facilities is approximately $80 \mathrm{LNG}$ vessels per year and therefore no affect on collision analysis is perceptible. On the contrary, it may even be considered that LNG vessels require high safety standards, and along with that we must consider the introduction of VTS, enhanced traffic lanes arrangements and advanced berthing facilities, extended reporting, improved escorting procedures - so that, almost paradoxically, the introduction of LNG facilities and ships should, in the end, actually increase the safety level in the Gulf of Trieste. On the other hand, although we may feel confident in our results specific to LNG ships and port activities, even the most cursory analysis of traffic in the Gulf of Trieste, including both ports, makes it clear that traffic control is a pressing issue and that each year with the increases in traffic the danger of a variety of accidents increases. At some point then, although the chances of an LNG carrier being involved in an accident may be slight, a worst case scenario involving this type of ship must be analyzed. Regarding an offshore terminal located inside the TSS, similar results are obtained in that, logically, a widening of the TSS results in an expected decrease in the chance of collisions; yet the addition of a stable structure in the TSS virtually invents a new possibility for disaster in that main engine failure can lead to a ship colliding with the structure.

\section{REFERENCES}

[1] Vanem, E., Antao, P., Ostvik, I., Del Castillo de Comas, F. (2008). Analyzing the risk of LNG carrier operations. Reliability Engineering \& System Safety, vol. 93, no. 9, p. 1328-1344, DOI:10.1016/j.ress.2007.07.007.

[2] Perkovič, M., David, M., Gucma, L., Przywarty, M. (2008). LNG terminals - cross-border influence, University of Ljubljana, Portorož. (In Slovenian)

[3] Risk Assessment LNG import Koper. (2009). Nautical and unloading operations. Report no/DNV Reg No.: /124UI0A-4, Rev 1, Det Norske Veritas, Hovik.

[4] Gucma, L., Perkovic, M., Przywarty, M. (2009). Assessment of influence of traffic intensity increase on collision probability in the gulf of Trieste. Annual of Navigation, no.15, p. 41-48

[5] Perkovic, M. (2002). AIS and global safety. Proceedings of $10^{\text {th }}$ International Symposium on Electronics in Transport, Electro-technical Society of Slovenia, Ljubljana.

[6] Gucma, L. (2003). Models of ship's traffic flow for the safety of marine engineering structures evaluation, Proceedings of European Safety \& Reliability Conference, p. 713-718.

[7] Gucma, L., Zalewski, P. (2003). Damage probability of offshore pipelines due to anchoring ships. Polish Maritime Research, vol. 10, no. 4, p. 6-12.

[8] Helcom Report (2006). Report on shipping accidents in the Baltic Sea area for the year 2005. Helsinki Commission Baltic Marine Environment Protection Commission, Helsinki.

[9] MAIB (2005). UK registered ships accident database, Maritime Accident Investigation Branch, Southampton.

[10] Sandia Report (2004). Guidance on Risk Analysis and Safety Implications of a Large Liquefied Natural Gas (LNG) Spill on Water, SAND 6258, Sandia National Laboratories, Albuquerque, New Mexico and Livermore.

[11] MEHRA (1999). Establishment of Marine Environmental High Risk Areas, Factors Influencing Vessel Risks in UK Waters, app. 6, Maritime and Coastguard Agency, London. 